\title{
Acquiring, Preserving, and Exhibiting a Comprehensive Collection of Vocal Music Recordings from the Early- to Mid-Twentieth Century
}

\author{
by Janneka Guise, Bryan Martin, James Mason, and Rebecca Shaw
}

\begin{abstract}
The Stratton-Clarke collection consists of approximately 200 linear feet of 78 and $331 / 3 \mathrm{rpm}$ records, and thousands of digitized recordings that represents a comprehensive history of early twentieth century recorded Western sound, specifically opera -- its artists, roles, and early legacy from $78 \mathrm{rpm}$ to early long play records. Along with some-ephemera and several pieces of historic playback equipment, a large financial gift will offset the costs of processing, preserving and providing access to the various formats represented in the collection. As the largest music research collection in Canada, the University of Toronto Music Library is fortunate to have the capacity to manage a donation of this magnitude. Each of our four authors has an important role to play to make the project a success. In this article we present a history and background of John Stratton, Stephen Clarke, and the collection itself, and document the many facets of a library taking on a donation of this size: donor relations and collaboration with the University's advancement team and other stakeholders; the project management involved in making space and designing workflow for cataloguing, processing, and storage; archival description of the 78s and ephemera; preservation of the digital objects and digitization strategies for the analog recordings; the challenges and opportunities of working with large financial gifts; teamwork and managing students; and future plans for physical and online exhibitions of the collection.
\end{abstract}

Janneka Guise (jan.guise@utoronto.ca) is the Head Librarian of the University of Toronto's Music Library, Bryan Martin (bryan.martin@utoronto.ca) is Technical Supervisor, James Mason (j.mason@utoronto.ca) is the Digital Initiatives and Metadata Librarian, and Rebecca Shaw (r.shaw@utoronto.ca) is the Music Archivist.

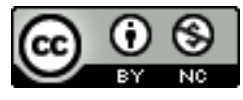

This work is licensed under a Creative Commons Attribution-NonCommercial 4.0 International License. 


\section{Introduction}

This article introduces a large donation of historical vocal music recordings, equipment, and ephemera called the Stratton-Clarke Collection. The donor transferred the collection to the University of Toronto Music Library in 2020.

We begin in Part One by providing a background of the collector and the donor and an overview of the administrative considerations of managing such a large gift. We then describe in Part Two the LP portion of the Stratton-Clarke Collection, what makes it interesting, and how we will catalogue it, process it, and integrate it into our circulating collections. Part Three covers the 78 collection and our treatment of it as an archival collection. Finally, in Part Four we talk about the digital audio files that accompany the collection, and our capacity for digital preservation and access at the University of Toronto.

\section{Part One: Background}

The collection is named for John Stratton, who began the collection, and for Stephen Clarke, friend of Stratton and Trustee of the Stratton Estate.

\section{John Stratton \& Stephen Clarke}

John Stratton was born in 1931 in Toronto. His parents were comfortably well off; he was raised in the high-end Rosedale neighbourhood and attended Upper Canada College, a prominent private boys' school in Toronto. Stratton's mother was from a musical family and was one of six daughters who were all accomplished amateur singers. In fact, Stratton's first singing teacher was his mother's oldest sister Kate.

Stratton started collecting records as a teenager in the 1940s. He continued his singing lessons with Florence Easton, a family friend from Toronto who was by then an opera singer of some renown. He graduated from Trinity College at the University of Toronto in 1954 and spent the following year in New York studying voice with Herbert Janssen. Upon his return to Toronto, he continued his vocal studies at the Royal Conservatory with such teachers as Aksel Schiøtz and Gina Chigna. These names, and those of other acquaintances he made during this time, began to appear in his record collection. His part-time work at record stores also helped his record collection blossom. He competed in Kiwanis Festivals and did well, even winning the silver tray one year. All this musical training and performing was a pastime only. He continued his studies at the University of Toronto for 15 years, finally completing his doctoral dissertation on Wittgenstein in 1969. From that point to 1995, Stratton taught philosophy at Ryerson University in Toronto. Stratton lived in the family home his whole life and died on January 2, 2001. 
Stratton wrote about music throughout his life, publishing articles for Opera Quarterly, the ARSC Journal, and the British Institute of Recorded Sound (part of the British Library). He also wrote liner notes, earning a Grammy nomination for the booklet to an LP issue of surviving Mapleson cylinders of live performances from the Metropolitan Opera House. The LP was issued in the mid-1980s. The Grammy nomination was in the "historical" category, and unfortunately a historical retrospective of Frank Sinatra won that year instead.

Stephen Clarke was born in 1946 in the Agincourt neighbourhood of Toronto, in less well-to-do circumstances than John Stratton. For Clarke's family, it was a big deal to travel downtown to see live performances. It was in 1958 when Clarke's father took him to the Toronto Symphony for the first time. A couple of years later Clarke became "hooked" on opera when he saw the Metropolitan Opera on Tour at Maple Leaf Gardens in a production of Faust. He bought a few records when he could, and his first opera set in 1959. Clarke was introduced to John Stratton through a mutual friend in 1967 while all three were students at Trinity College together. They would go to Stratton's house and listen to his records. Clarke was studying Law, taking voice lessons, and singing in choirs. He competed in Kiwanis Festivals and won medals. He studied with Howell Glynn (Royal Conservatory of Music), with Elizabeth Bensen Guy and her mother-in-law Greta Kraus (both at the $\mathrm{U}$ of T Faculty of Music), and with Gladys Whitehead (Hamilton Conservatory). For several years he kept up a singing career while working as a lawyer, but in 1978 he reached a crossroads and realized he could not devote equal energy to both pursuits. He had been offered a partnership in his law firm, so he stepped back from professional music gigs while keeping music in his life as a serious pastime. He and Stratton remained friends for the rest of Stratton's life, and Stratton made Clarke his estate trustee.

John Stratton collected records from the 1940s throughout his life, focusing on solo vocal and opera. He had many record collecting friends near and far. He enjoyed recording himself singing and made many recordings over the years at Avey Byram's flat with Byram at the piano. Late in Stratton's life, Stephen Clarke worked with Stratton to create a CD from the best examples from the hundreds of reel-to-reel tapes he had produced. Stratton heard the CD just before he died and was pleased with it.

\section{Contents/Scope of collection}

The collection spans the early- to late-twentieth century. There are approximately 200 linear feet of physical sound recordings (mostly $331 / 3$ and $78 \mathrm{rpm}$, with 5 linear feet of $45 \mathrm{rpm}$, and 80 linear feet of CDs). There is also a terabyte of digital audio files. After Stratton died, Clarke took over the collection and started filling gaps. In addition to buying records from auctions and private collectors, he began acquiring digital audio files. He obtained thousands of dubbings of important recordings through Ward Marston, who had permission to dub them prior to their going to auction. There is a hard drive containing 6,000 recordings from the collection of the late John Paul Getty, Jr. There is 
another hard drive containing both flat and re-engineered transfers of the complete output of Historic Masters. Historic Masters is an organization which holds over thirty years of re-issued, previously unpublished material from the EMI Archive in the United Kingdom as vinyl 78 rpm discs, and Clarke is its current Chairperson.

The ephemera in the collection includes John Stratton's papers, photographs, and correspondence with singers and discographers.

There are several pieces of modern and historic playback equipment in the collection. Some examples include a turntable designed for restoration work on early recordings, one DAT machine, a professional CD player with the ability to vary the speed of playback, a CD recorder, a mixer, two pre-amps designed for playback of early recordings, a pair of CEDAR noise reduction decks, three reel-to-reel tape decks in various formats, and a collection of styli of various sizes. Some of this equipment will be stored on a "media cart" in the Music Library, for use by faculty and researchers. Finally, there are three antique gramophones which will be displayed in the Music Library to help showcase the collection and will be used on rare occasions for demonstrations: a Victor $\mathrm{VI}$, an Edison Amberol cylinder machine, and a portable 78 player called a Cameraphone.

\section{Why the U of T Music Library?}

Before John Stratton died, he decided his assets should be used in furthering the teaching of singing. He was always hopeful that the University of Toronto would take it, given his long connection to the institution. He left it up to Clarke to decide how to disperse the collection, and Clarke decided to donate it rather than break the collection up to sell it.

The University of Toronto Music Library is an excellent choice as recipient of this collection. As the largest music research collection in Canada, it is already well-known and sought-after by researchers for its comprehensive published and archival collections. $U$ of T's Downsview facility is well-positioned to house rare and special collections in state-of-the-art climate control. The Music Library has human and financial resources that are unmatched by any other music library in the country. These resources allow us to design and implement workflows for managing such a large incoming donation, and assign technical, archival, and metadata tasks to specialists in those areas. The $U$ of $T$ Libraries Media Commons, which is a sound and moving image archive, will be an important partner in maintaining the historic and specialized equipment that is coming with the donation.

\section{Donor relations \& Social Capital}

The memorandum of understanding (MOU) between the University of Toronto and the Estate of John Stratton was signed in 2016. The MOU pre-dates the arrival of the new Music Library Director (Jan Guise) in 2017. Part of Jan's steep learning curve in the Director position was gaining insight and background into the Stratton-Clarke Collection. She had come from an institution that had 
faced steep budget and staffing cuts and had never been in a position to take on such a mighty donation. Now, she found herself with the space, human and financial resources, administrative support, and organizational culture for such an enterprise. She first met Stephen Clarke early in her tenure over lunch with the Director of Advancement for the Faculty of Music. After lunch they visited the collection, which was nicely laid out in its own apartment in Toronto's Annex neighbourhood near the University. While the logistics of accepting such a large collection can seem overwhelming, the MOU stated that the collection would be transferred to the University "no later than September 2021." In 2017, this meant there was still time to plan.

What makes the Stratton-Clarke Collection truly exceptional is the large financial gift that accompanies it. Provisions were written into the MOU to use the money for processing, preserving, and promoting the collection. The language provides for unrestricted use of the funds which will allow the Music Library great flexibility in hiring appropriate staff to process the collection, paying for supplies (e.g., archival boxes), and even organizing a lecture series to highlight aspects of the collection.

Stephen Clarke arranged for the move of the collection's LPs to the Music Library in early Spring 2020, just prior to the COVID-19 shut-down. At the time of writing, plans are afoot to move the remainder of the collection (78s, ephemera, and equipment) in late August while the Library is still closed to the public. Staff have begun cataloguing and describing the collection remotely from Clarke's meticulous lists, and this work will continue in 2020-21 as COVID-19 restrictions are lifted and staff return to onsite work.

\section{Administrative Aspects}

Shortly after the MOU was signed (May 2016), the Music Library changed governance structures and was now under the auspices of the Central Library system rather than the Faculty of Music. This meant the Music Library now had a wealth of new resources at our disposal, but a big part of Jan's job was building social capital within this new structure: navigating bureaucracies, identifying collaborators, and learning "who is in charge of what." For example: How does the Central Advancement team manage a financial gift of this nature, how can we ensure the funds are as unrestricted as possible, and how do we spend and account for that money? To manage this donation and financial gift, Jan is working with three distinct Advancement Teams (one for the Faculty of Music, one for the Library system, and the Central Advancement team for the University as a whole). In order to be a good steward, she needs to understand their separate roles in dealing with such a gift.

The Music Library does not have sufficient shelf space to house the collection, nor do we have the proper climate control and limited access necessary to preserve a collection like this. We therefore decided early on that the $U$ of T Libraries' Downsview facility would be the collection's new home. 
However, Music Library staff would catalogue, describe, digitize, and process the collection prior to transferring it to Downsview. Digitization will ultimately make most of the collection available ondemand to researchers, and anyone serious enough to want to work with the originals could recall them to the music library's reading room. Since LPs are more robust than $78 \mathrm{~s}$, we decided to treat them the same as our own LP collection and catalogue them as part of our circulating collection. They will be discoverable in our public catalogue and may circulate from Downsview. 78 rpm discs are fragile and represent a particular period in recording history and performance practice for the purposes of recording. $78 \mathrm{rpm}$ discs also represent a type of primary source in recording history, since later formats like LPs and CDs are often reissues of older recordings. We therefore decided to treat the $78 \mathrm{~s}$ as an archival collection.

Stephen Clarke, the Dean of Music, and the Advancement teams have been very supportive of the idea of the collection being stored at Downsview. However, Stephen Clarke expects to continue to use the collection himself for teaching and research, and everyone involved wanted to find a way of showcasing the collection in the Music Library even though most of it would live off-site. Clarke has therefore identified two shelves' worth of "highlights" from the collection that will stay in the Music Library as a sort of "tasting menu." Together with the media cart (mentioned above) that will house some of the playback equipment from the donation, these highlights can be used by visiting researchers or seminar classes as exemplars of the whole collection.

\section{Part Two: The Long Play Records}

The Music Library's collection of commercially released recorded sound includes recordings in many formats including legacy formats dating as far back as the late-1800s with wax cylinders, and piano rolls. We also have several thousand $78 \mathrm{rpm}$ recordings from the early twentieth century, a few "Edison discs," and tape formats such as $1 / 4$-inch and $1 / 2$-inch reel-to-reel tapes and audio cassettes. One of the more common formats in our collection is the compact disc, yet our LP collection is still larger. We have over 100,000 vinyl LP recordings of various sizes: 10 -inch, 16 -inch, but mostly 12 inch.

The scope of the Music Library's sound recording collection is substantial. There are aspects of the collection that are well curated and comprehensive, such as European art music, or special labels like Smithsonian Folkways. However, much of the collection was built from donations which has resulted in a spotty collection in certain areas. For example, we hold over forty Miles Davis titles on LP, but not "Kind of Blue," or "Bitches Brew" (though we later acquired these on CD or streaming services).

The Stratton-Clarke gift will add close to 3,000 titles to our existing collection. This constitutes about 92 linear feet. Many are multi-disc sets (full operas for example), others are single disc 
releases. There are, however, many duplicates within the donation, and many more duplicates of items already in our collection. We plan to remove duplicates as we process and catalogue the collection (likely keeping Stephen Clarke's donated copy and discarding our own, since his are in pristine condition).

This donation is a well-curated collection of primarily vocal music with three main categories of content:

1. Opera recordings, including highlights and selections,

2. Vocal recitals, and

3. Miscellaneous European art music (motets, concertos, symphonies, etc.).

The first two constitute the majority of the collection, and are the items in the best condition.

Operas

This portion of the collection largely focuses on Classical and Romantic era opera. In total, there are about 40 composers whose works constitute over 1,000 titles. Wagner, Verdi and Puccini, representing late romantic opera, constitute over $30 \%$ of the opera recordings. Just 10 composers constitute $50 \%$ of the opera donation (see Figure 1 ).

Figure 1: Distribution of opera composers in Stratton-Clark collection (by percentage)

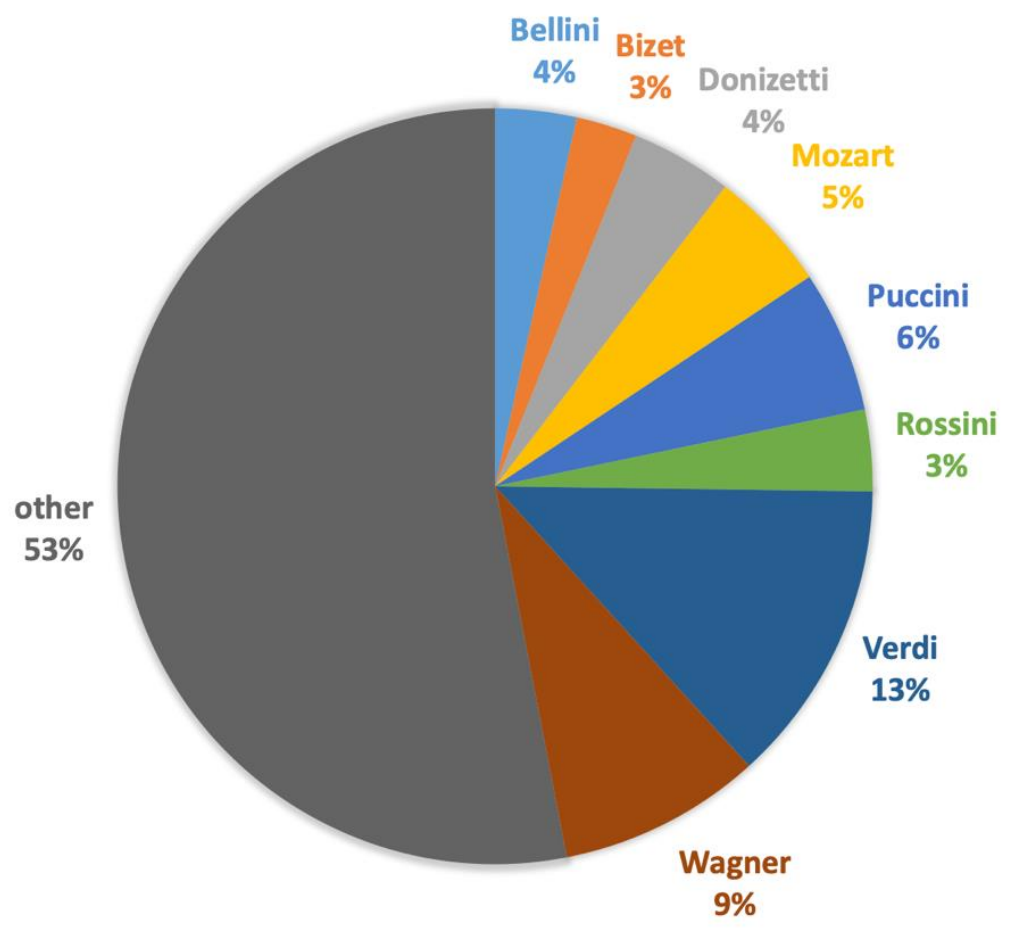


Most composers and titles represent common and standard repertoire. Multiple examples of titles are represented, for example, ten different versions of Bellini's bel canto opera Norma. This gives our researchers the ability to compare different recordings of the same work, examining vocal performances by major artists, and interpretations by leading conductors. One release of Norma from 1954 (Ang. 35148-50) released by Angel records features Maria Meneghini Callas as Norma, with Tullio Serafin leading the La Scala Orchestra, while another from 1957, from RCA (LSC-6202) released in 1973 features Montserrat Caballe as Norma singing with Placido Domingo, and Carlo Felice Cillario conducting the London Philharmonic. These recordings will offer many options for comparative research or for studying different interpretations by performers and conductors.

The album covers have also been a source of great amusement! The liner notes also bring immense value.

\section{Vocal Recitals}

The vocal recitals constitute about half the donation. Many of the recital recordings feature singers who established their careers during the early years of recording history (many of the LPs being reissued from original cylinders or 78 releases). In all, there are close to 100 different singers featured in these recitals.

\section{Figure 2: Birth and premier dates of singers in the Stratton-Clark collection}

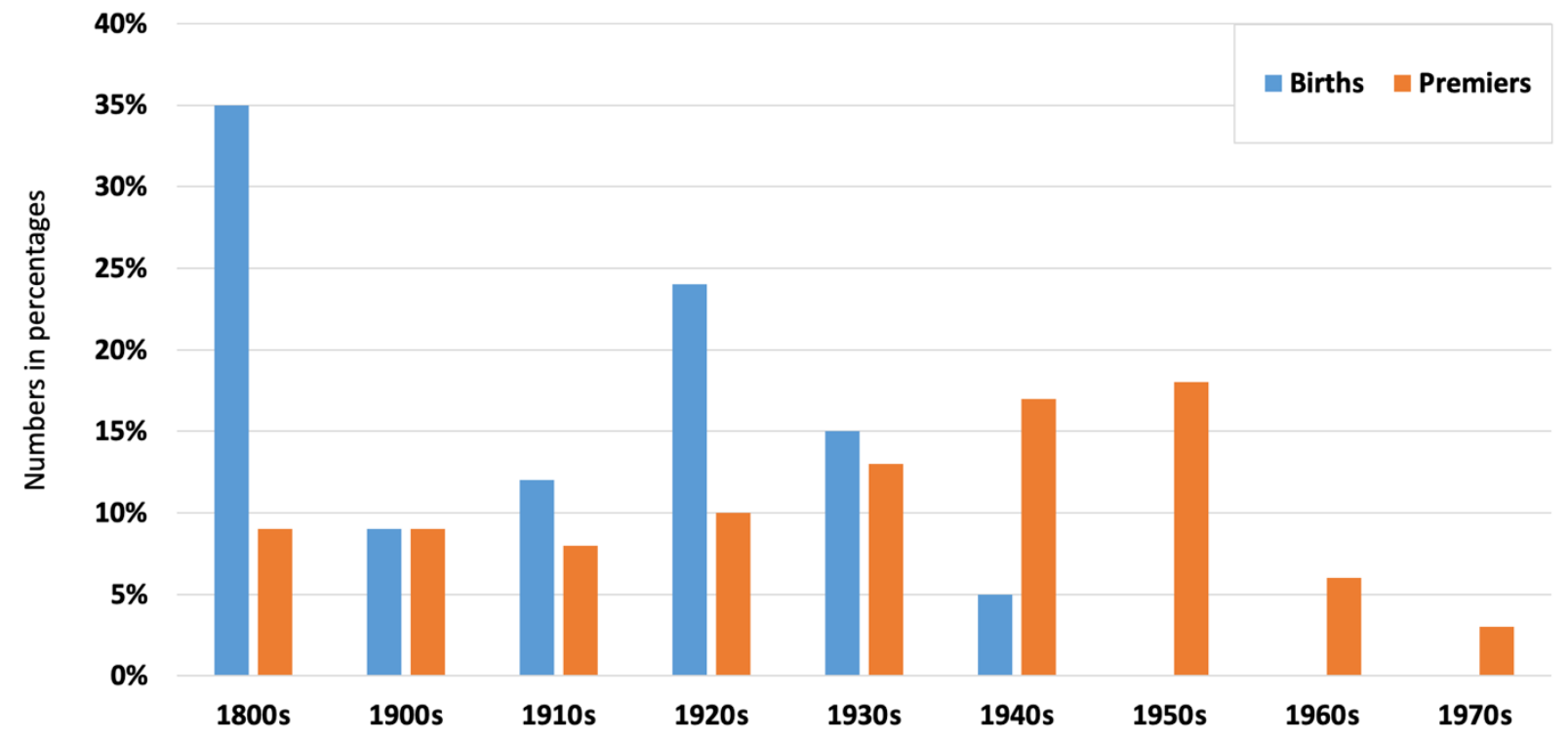

As you can see in Figure 2, 35\% of the singers were born in the 1800 s. Most of these artists had debuts before the mid-1900s as well. As this part of the collection consists of LPs, a relatively later technology, the debuts skew a little to the mid-century as the new releases start to augment the reissue recordings being collected. 
The recitals are comprised largely of singers known for their operatic careers. Some examples are Luciano Pavarotti, known originally for his opera roles, later branching out to popular music; Birgit Nilsson, a dramatic soprano known for her interpretations of Wagner and Strauss; Lilli Lehmann, a versatile German operatic soprano; Maggie Teyte, an English operatic soprano. The singers featured in this part of the collection demonstrate John Stratton's curation of star European and North American performers from the early part of the twentieth century.

\section{Miscellaneous and Publishers}

Many publishers are represented among the recordings, from major producers to lesser known or more "boutique" labels. The majority of the recordings, however, are releases from major companies.

Figure 3: Labels represented in the Stratton-Clarke collection (by percentage)

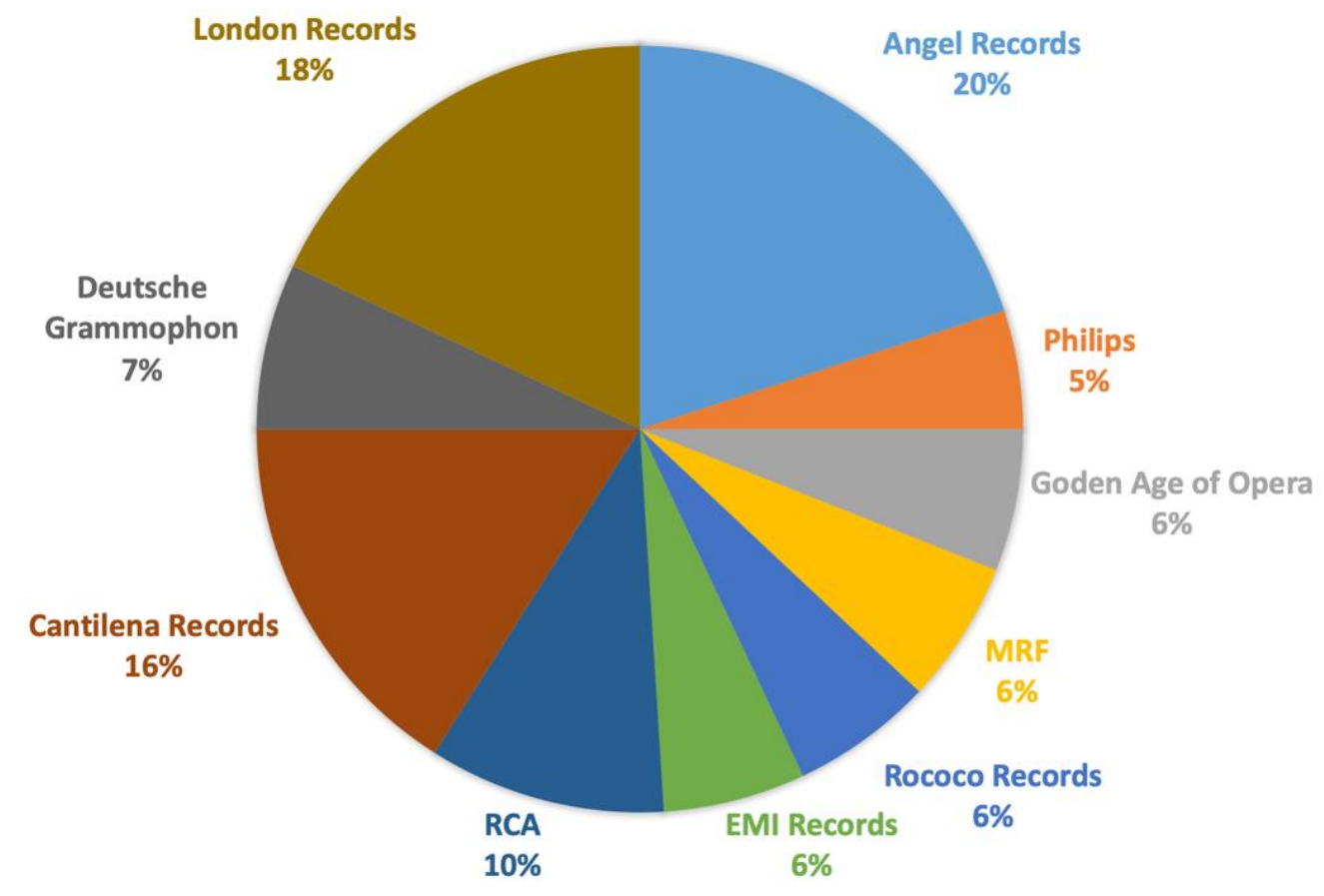

Of the albums processed so far (531 in total), the top 10 labels constitute close to $54 \%$ of the releases (see Figure 3). We have catalogued discs from over 100 different labels. While some labels have only one or two titles represented, major labels such as RCA, Philips and London are well represented and reissue labels like Cantilena, Rococo and Golden Age of Opera are also well represented. It remains to be seen whether this breakdown will hold true for the whole collection once it is fully processed.

Many labels released material that is difficult to access in original formats. Reissues offer researchers access to some of the earliest examples of recorded music: for example, reprints, dubs 
from cylinders and 78s, private sale items, live and off-the-air recordings, items recorded from acetates, and first-generation reel tapes of live recordings. Some examples of labels in this collection that reissue historic material include Golden Age of Opera, Cantelena, Rococo, MRF, BJR, and A.N.N.A records. Golden Age of Opera (in library catalogues often referred to as "celebrity records") was a series / label produced and released by Edward J. Smith, issuing early recordings of opera and vocal recitals. Golden Age of Opera releases offer rare examples of performances originally recorded for radio or held in private collections. Cantelena Records was owned and run by John Stratton himself. The label focussed on reissues of famous singers from the earliest recordings including reissues of cylinder recordings and $78 \mathrm{rpm}$ recordings. Rococo, which also distributed Cantelena Records, had a similar focus on early opera and vocal repertoire. MRF, a small "private recording" label, often reissued from previous releases, including those released by Golden Age of Opera. Unique Opera and A.N.N.A are also labels run by Edward J. Smith with similar mandates as Golden Age. BJR issues recordings of original historic material which are occasionally later used by others including EMI, which is a testament to the quality of their reissues. The collection also includes a complete set of Historical Recording Enterprise recordings which focus on early vocal repertoire reissues. These speciality labels give the collection a richness of primary examples of the vocal art form during the early part of recording history.

While cataloguing this donation into our existent collection, description is of paramount importance. We need to represent the relevant data points of the contents and unique nature of this collection so that researchers can find what they are looking for. Proper description also makes connections with other relevant materials. One important aspect of this collection is that it offers a comprehensive representation of star performers of a generation when recording was in its infancy. The description of the LPs must facilitate the discovery of these artists. We cannot know which questions researchers might ask when searching this collection, so we will provide a deep level of description to facilitate a variety of potential information needs. For example, researchers might investigate publishing trends in different countries, particular vocal styles or performers, or the history of an orchestra or performing arts institution.

We provide standard information such as titles, composers, and artists, but also detailed publication information including place and date of recording, of publication, and of copyright. We also include information on distributors, publishers, and manufacturers when known (e.g., publisher numbers, matrix numbers). We feel name entries are of particular importance with a collection like this as performers, conductors, or ensembles may be as interesting to researchers as the composer or title of a work. While there can sometimes be a long list of names to document, we feel the effort is necessary to reflect the unique value of this collection. We will include detailed contents notes when necessary to capture additional information.

Many of these data points need to be structured in a standardized way, conforming to authorized formats issued by collective bodies. We often use Library of Congress authority records for names, 
as an example. Along with names, other structured data points of importance are subjects and uniform titles. This is true for personal names like Tchaikovsky as well as corporate names such as Orchestra Sinfonica di Torino della RAI (the Italian orchestra), or Melodia (a record label). The name Tchaikovsky is a good example of why good authority records are necessary: in German it can be transliterated as Tschaikowski, in Italian as Ciajkovskij, and the original Cyrillic being Чайковский. Due to historical practice, we still often find Tchaikovsky's music filed under " $C$ " in some library catalogues, including our own. These different spellings can confuse researchers and make it difficult to find everything by Tchaikovsky in a catalogue search. Uniformity of description brings all instances of a name under one commonly used heading, so researchers will find these instances no matter which spelling they use in their search. Looking more closely at Orchestra Sinfonica di Torino della RAl, we see that the authorized (by the Library of Congress authority file) form of the name is "Radiotelevisione italiana. Orchestra sinfonica di Torino." Linking to that name helps us remove ambiguity. This can help us, for example, distinguish this orchestra from a more modern orchestra from Turin known as "RAI National Symphony Orchestra". GOST 7.79-2000 is very common standard for Romanizing the Cyrillic alphabet. Google Translate uses this standard, for example, to render the Russian record publisher's name мелодия as melodiya. By contrast, the ALA-LC transliteration table transliterates it as Melodía. Other transliterations can include Melodiâ and Melodia, or even a direct translation: Melody. When describing LPs published by this company, we need to recognize the various ways our users may search for the items, and the complexities inherent in that task.

With uniform identifiers links can be made organically between names, places, events, concepts, and titles. For example, "Maria Callas" (name) can be linked to "Bel Canto" (concept). "Tullio Serafin" (name) can be linked to "Metropolitan opera" (organization). Links to composers like Bellini, and to titles like Norma to publishers like Angel Records can be dynamically generated. Such links allow for serendipitous "discoveries" to be made by researchers.

Recognizing the importance of a thorough and comprehensive description clearly augments the task of processing and storing a donation of this size. We need to find efficiencies in this work since the task of processing this donation needs to find its place amongst a list of other tasks that need to be maintained. We need to build workflows based on clearly defined priorities and goals. We need to remove duplicate items already in our collection, for example. Incorporating the LPs from this donation into our collection will augment our collection's value to researchers and make available items that are difficult to find and listen to elsewhere.

\section{Part Three: The 78 rpm Collection}

The Stratton-Clarke collection of $78 \mathrm{rpm}$ records spans nearly the entire history of 78 record production, from acoustic recordings to early electronic recordings and beyond, covering the first 
half of the twentieth century. It consists of approximately 7,000 records, pressed on primarily shellac discs, ranging from 7 to 14 inches in diameter. The more than 11,000 individual recordings capture performances from approximately 1,000 individuals (predominantly vocalists), performing the works of more than 900 different composers on at least 100 different labels. This section will provide a general overview of the 78s, explain how and why the collection is being described as an archival collection, and itemize the efforts that will be made to maximize the discoverability of its recordings. It will also briefly discuss decisions regarding the storage of the $78 \mathrm{~s}$ that were made to balance accessibility, preservation concerns, and space limitations within the Music Library.

Overview of the 78-rpm collection and the collecting policies of Stratton and Clarke Throughout the acquisition and curation of the 78 records, John Stratton and Stephen Clarke followed a loose collection policy with four main points of interest: the "Golden age of singing," the Mapleson recordings, Canadian performers, and Russian recordings made prior to the revolution (1917-1923). Recordings from the so-called golden age of singing were made prior to the First World War, including artists like tenor Enrico Caruso (1873-1921), soprano Nellie Melba (18611931), baritone Mattia Battistini (1856-1928), tenor John McCormack (1884-1945), and tenor Dmitrii Alekseevich Smirnov (1882-1944). Of the 11,165 recordings processed to date (November 16, 2020) in the Stratton-Clarke $78 \mathrm{rpm}$ collection, about a third $(3,690)$ were created prior to July 28, 1914. For a complete overview of the chronological spread of the collection, see Figure 4.

Figure 4: Chronological spread of 11,165 of the Stratton-Clarke 78s (approximately 99\% of the complete collection

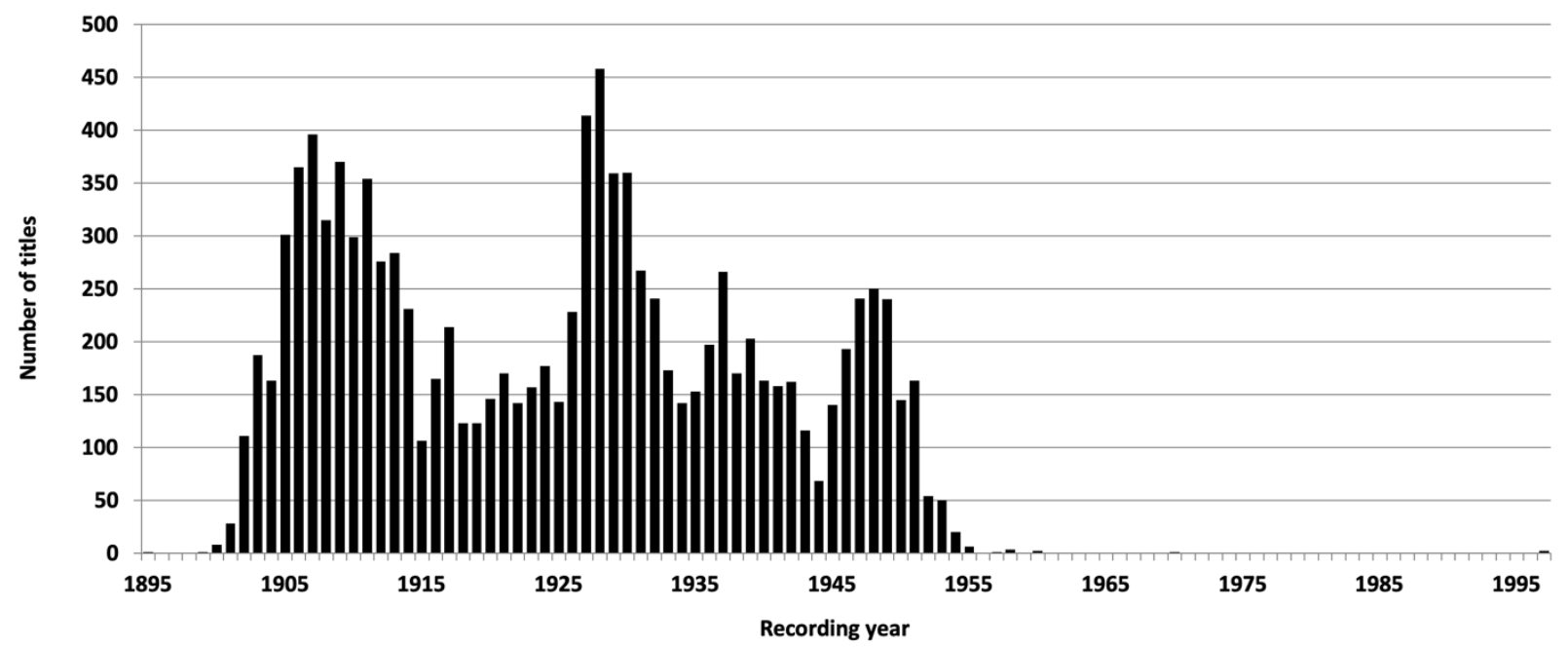

The Mapleson recordings are a well-known collection of wax cylinder recordings created by Lionel Mapleson, librarian for the Metropolitan Opera, and currently held in the Rodgers and Hammerstein Archives of Recorded Sound at the New York Public Library. The recordings of live 
Metropolitan Opera performances were made between March 30, 1900 and February 1904. Over 30 years later, William Seltsam, director of the International Record Collectors Club (IRCC), produced a series of $78 \mathrm{rpm}$ records from the original wax cylinders. Stratton's research interest in this collection is intimated in his essay "What can we hear? The Maplesons as Research Tools," which accompanies an anthology of LPs issued by the Rodgers and Hammerstein Archives (1985):

There are moments of striking vocal brilliance to be heard. Indeed, virtually every celebrated name provides evidence that he or she deserved a great reputation... The performances in general are unexpectedly direct and honest. Of course, there is frequently evident an eagerness to make big effects that does contrast somewhat with present-day practice, but to my ears what we hear never breaks out of the frame of an overall performance. ${ }^{1}$

The basis for this description of the Mapleson recordings was undoubtedly Stratton's personal collection of IRCC re-releases of the Mapleson cylinders.

Stratton and Clarke's third collecting area, early Canadian singers, is of particular significance to the Music Library, given its concordance with the Library's existing archival and special collections. Singers include tenor Edward Johnson (1878-1959), Florestine Fortier, ([1878?]-1933), soprano Jeanne Dusseau (1893-1979), soprano Emma Albani (1847-1930), soprano Lois Marshall (19241997), and soprano Pauline Donalda (1882-1970), among others. The Music Library already holds the Edward Johnson Collection, which includes photographs, programs, correspondence, manuscripts of songs written for him, and scrapbooks; the more than 40 recordings of Johnson between 1914 and 1928 in the Stratton-Clarke Collection will complement these holdings. Stratton also had a "soft spot" for singers that he encountered throughout his career and personal life, including soprano Florence Easton (1884-1955), soprano Gina Cigna (1900-2001), tenor Aksel Schiøtz (1906-1975), and baritone Herbert Janssen (1892-1965). ${ }^{2}$ The collection also includes a few select instrumental recordings, including the Canadian violinist Kathleen Parlow (1890-1963), whose archive is held at the Music Library, and the Canadian conductor Sir Ernest MacMillan (1893-1973), conducting the Toronto Symphony Orchestra.

Both Stratton and Clarke were involved in the collection of recordings made in Russia prior to the revolution (1917-1923), and through their involvement with the Historic Masters label, they funded releases of early Russian recordings as $78 \mathrm{rpm}$ records. According to Stephen Clarke, the Russian recordings are some of the best items in the collection, and also some of the rarest. ${ }^{3}$ Recordings of the soprano Medeia Meľ-Figner (1859-1952), for example, are exceedingly rare; the Stratton-Clarke Collection includes nine of her recordings. While the Stratton-Clarke collection of $78 \mathrm{~s}$ includes

\footnotetext{
${ }^{1}$ William Ashbrook, "The Mapleson Cylinders: Complete Edition, 1900-1904," The Opera Quarterly 4, no. 2 (January 1986): 110-116. doi:10.1093/oq/4.2.110.

${ }^{2}$ Stephen Clarke, email message to author, May 4, 2020.

${ }^{3}$ Clarke, email.
} 
recordings that fall outside of these four main collection areas, driven in part by Stratton and Clarke's personal research and listening interests, in part by their historical value, and in part by the rarity of the recordings, these four areas account for the vast majority of their collection decisions. Future researchers and users of the collection will undoubtedly create new groupings, but it is important to understand the origins of the collection and the curatorial intentions that underpin it.

\section{Archival collection}

The 78s are, and will be, described as an archival collection, rather than catalogued in our main library catalogue like the LPs. An archival collection differs from a library collection in many respects. Briefly, archives collect materials that are unique, specialized, or rare, and their intellectual arrangement retains or attempts to recreate that implemented by the creator or collector. This maintains the research value that arises from observing a collection of materials as representative of the efforts and activities of its creator or collector, rather than focussing predominantly on the research value of distinct items only. The collection of Stratton-Clarke 78s includes both unpublished and published materials. Based on a simplified division of unpublished materials in archives and published materials in libraries, the former is immediately, easily defined as archival. They are one-of-a-kind items that, if lost, cannot be replaced. For example, the StrattonClarke Collection includes a private recording by Florestine Fortier ([1878?]-1933) of the aria "Care Selve" (Come, beloved) from Atalanta by Georg Frideric Handel (see Figure 5). Fortier (née Bélanger) was a soprano from Montreal. According to her obituary in the New York Times, she was prominent in Montreal musical circles for over 30 years and premiered many songs by the Russian composer Nicolaï Medtner in North America. She could "sing from memory 100 songs of Hugo Wolf alone. Many of the songs of Schubert, Schumann, and Brahms were at her command at a moment's notice, [...and] she specialized in the soprano parts of Wagnerian opera." 4 Despite her reported virtuosity and skill as a performer, this unpublished record is the only known recording of her voice.

Published 78s, on the other hand, may also exist elsewhere, so are not immediately archival. However, part of the mandate of an archive is to maintain the integrity of a collection, both physically and intellectually. If the published and unpublished parts of the collection were separated, this integrity would be lost, and the research value of the collection would also be distorted. The fragility and rarity of the recordings-including those that are published-also contributed to our decision to keep the 78s as a complete archival collection. The LPs, on the other hand, do not share the same physical risks, and are commercially released, published recordings. A few LPs, particularly test pressings featuring John Stratton, will also be part of the archival collection for the aforementioned reasons.

\footnotetext{
4 “Mrs. L. M. Fortier, singer, dies at 55: Work recently composed by Medtner was dedicated to Montreal artist," The New York Times (January 3, 1933).
} 
Figure 5: Handwritten label (possibly in the performer's hand) of Florestine Fortier's performance of "Care Selve" from the opera Atalanta by Georg Frideric Handel.

Note: The label includes the two opening measures for the right hand of the piano accompaniment.

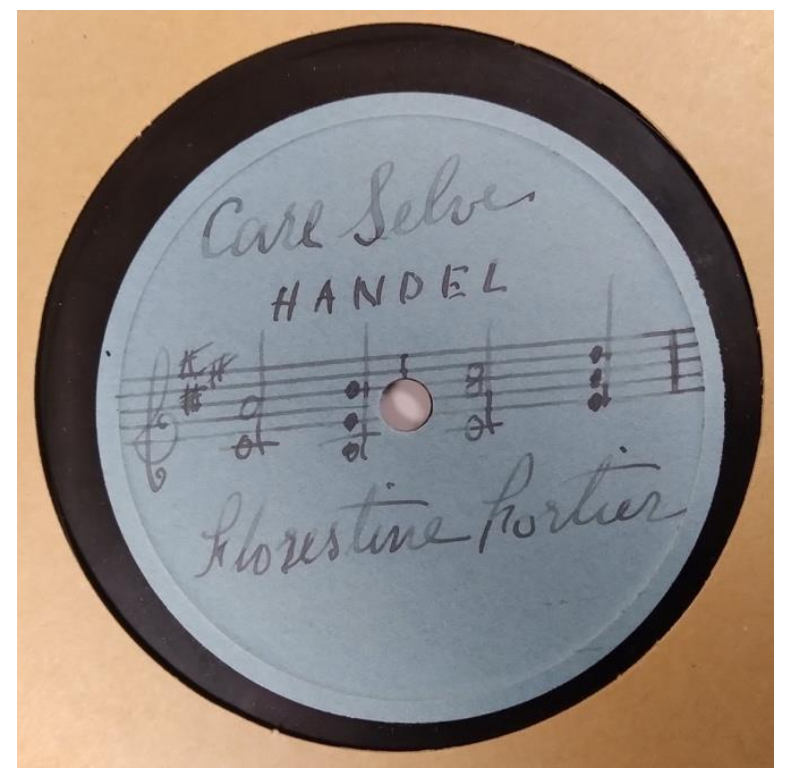

\section{Physical and intellectual accessibility vs. Storage capacity}

Some of the Stratton-Clarke 78s will be kept on hand at the Music Library, while the remainder of the collection will be stored off-site. The decision to split the physical storage of this collection was made to balance accessibility, preservation concerns, and space limitations within the Library proper. The University of Toronto Libraries offsite storage facility, Downsview, has the advantage of being a climate-controlled space, ideal for the long-term storage of this (and other) collections, whilst the Music Library has the advantage of ready access to materials. Due to the size of the collection, it is not practical to store it in its entirety onsite, so a compromise was made that the most valuable and historically interesting recordings (as selected by Clarke), would stay onsite, whilst the rest would be stored offsite. Offsite recordings will still be accessible to our patrons and the public, but requests to access them must be made in advance of visiting the library to allow time for their physical transportation. The records are all stored in archival-quality boxes and will be retrieved at the box-level to preserve the physical integrity of the discs. Access to the collection will be mediated by an archivist or librarian, as with all our archival, rare, and special collections. Some of our less-frequently-accessed archival collections are already stored offsite and may be accessed in this manner, so while the Stratton-Clarke 78 collection is the only divided collection among them, it is not the only one that will be accessed in this way.

Clarke selected approximately 1,000 recordings to remain in the Music Library. His selections were made based on the 20 years he has spent giving presentations on the collection. When asked to 
describe his selection process, Clarke intimated that those that he regularly used in his lectures were based on a number of factors, including:

...how good, how rare, and how illustrative of the talent of early singers a recording was. It was also motivated by the fact that the repertory sung in early recordings was so different from what any recitalist would choose these days and I wanted to be able to illustrate some of the recherché rep[ertoire] that was recorded.... also wanted to keep some records that were significant in the history of recording... [as well as] some interesting creator performances. $^{5}$

Clarke's "interesting creator performances" include recordings of Richard Strauss (1864-1949) accompanying vocalists on piano in performances of his own works, and recordings of traditional Hungarian songs arranged by Zoltán Kodály (1882-1967) and accompanied on piano by Béla Bartók (1881-1945).

To ensure that both those $78 \mathrm{~s}$ stored onsite and those that are stored offsite are as accessible as possible, the description of each recording, and the resulting finding aid for the collection, will be as robust and standardized as possible to ease discoverability within the collection. Finding aids at the University of Toronto are held in Discover Archives, which uses the open-source application Access to Memory (or AtoM). While there are different metadata standards that one can use in Discover Archives, we chose to describe this collection according to the Canadian archival description standard, Rules for Archival Description (or RAD) because it allowed for the granular level of description is needed for this collection to maximize discoverability and enable a variety of research queries and uses.

Depending on the needs of a collection and time constraints, an archivist may provide various levels of description. For some fonds or collections, a top-level description might suffice in order to provide a basic level of access to the collection. For others, one might describe at the series level; for example, it might be sufficient to describe the correspondence of an individual as a group without itemizing the individual letters contained therein. For this particular collection, however, this would be insufficient. As stated previously, the collection has research value as a whole, but it is only when one knows the contents of the collection that its complete research value is realized. Moreover, while some may be interested in the collection in its entirety, others may be drawn in by a particular vocalist, composer, piece, label, date, or location. To enable these sorts of inquiries, easy discovery within the collection, and easy retrieval of items in both storage locations, the collection is described at the item-level, with multiple points of entry by which researchers can explore the collection (see Table 1). Description at the item-level will also allow the inclusion of digital surrogates of the recordings at a later date.

\footnotetext{
${ }^{5}$ Clarke, email.
} 
Table 1. Summary of key metadata elements for the item-level description of $78 \mathrm{rpm}$ records in the Stratton-Clarke Collection according to the Rules for Archival Description (RAD) ${ }^{6}$

Note: Example 1 is for a recording of "Stridono lassù" from the Italian opera Pagliacci by Ruggero Leoncavallo, sung in French by Aino Ackto. Example 2 is for a recording of "O cease thy singing maiden fair" by Sergei Rachmaninoff, sung in English by John McCormack.

\begin{tabular}{|c|c|c|c|}
\hline $\begin{array}{l}\text { RAD element } \\
\text { and rule }\end{array}$ & $\begin{array}{l}\text { Application to the Stratton- } \\
\text { Clarke } 78 \text { collection }\end{array}$ & Example 1 & Example 2 \\
\hline 8.1B Title proper & $\begin{array}{l}\text { Transcribe directly from the } \\
\text { disc label. If a title is not } \\
\text { available on the label, use a } \\
\text { Supplied title proper. }\end{array}$ & $\begin{array}{l}\text { Paillasse : Air de } \\
\text { Nedda }\end{array}$ & $\begin{array}{l}\text { O cease thy singing } \\
\text { maiden fair, op. } 4 \text {, no. } \\
4\end{array}$ \\
\hline $\begin{array}{l}\text { 8.1D Parallel } \\
\text { titles }\end{array}$ & $\begin{array}{l}\text { Include the uniform title and } \\
\text { any alternate titles for the } \\
\text { recording (deviation from strict } \\
\text { application of RAD). }\end{array}$ & $\begin{array}{l}\text { Pagliacci. Stridono } \\
\text { lassù }\end{array}$ & $\begin{array}{l}\text { Romansy, op. } 4 \text {. Ne pol̆, } \\
\text { krasavitsa, pri mne }\end{array}$ \\
\hline $\begin{array}{l}\text { 8.1F Statements } \\
\text { of responsibility }\end{array}$ & $\begin{array}{l}\text { Record the name of the } \\
\text { composer, arranger, and/or } \\
\text { lyricist. Format each name } \\
\text { according to that provided in } \\
\text { the Virtual International } \\
\text { Authority File (VIAF). Indicate } \\
\text { the role of the individual } \\
\text { (composer, arranger, lyricist) in } \\
\text { brackets following their name. }\end{array}$ & $\begin{array}{l}\text { Leoncavallo, Ruggero, } \\
1857-1919 \\
\text { (composer) }\end{array}$ & $\begin{array}{l}\text { Rachmaninoff, Sergei, } \\
\text { 1873-1943 (composer) }\end{array}$ \\
\hline $\begin{array}{l}\text { 8.4B1 Date(s) of } \\
\text { creation }\end{array}$ & $\begin{array}{l}\text { Record the date of recording. If } \\
\text { the recording is a re-release of } \\
\text { an earlier issue, both dates } \\
\text { may be included. Dates are } \\
\text { taken from various } \\
\text { discographies, including, but } \\
\text { not limited to the Kelly } \\
\text { Database and the Discography } \\
\text { of American Historical } \\
\text { Recordings (DAHR). The source } \\
\text { of the date should be included } \\
\text { in the description. }\end{array}$ & December 1902 & April 2, 1919 \\
\hline
\end{tabular}

${ }^{6}$ Rules for Archival Description (Ottawa, Canada: Bureau of Canadian Archivists, 1990, revised July 2008). 


\begin{tabular}{|c|c|c|c|}
\hline $\begin{array}{l}8.4 \mathrm{C} \text { Place of } \\
\text { broadcast, } \\
\text { publication, } \\
\text { distribution, etc. }\end{array}$ & $\begin{array}{l}\text { Notate the location of } \\
\text { recording, if known. }\end{array}$ & Paris, France & Camden, New Jersey \\
\hline $\begin{array}{l}\text { 8.5 Physical } \\
\text { description area }\end{array}$ & $\begin{array}{l}\text { Record the extent and } \\
\text { dimensions of item, including } \\
\text { the size of the disc and playing } \\
\text { speed. }\end{array}$ & $\begin{array}{l}1 \text { side of } 1 \text { audio disc : } \\
78 \mathrm{rpm} ; 10 \mathrm{in} .\end{array}$ & $\begin{array}{l}1 \text { side of } 1 \text { audio disc : } \\
78 \mathrm{rpm} ; 10 \mathrm{in} .\end{array}$ \\
\hline $\begin{array}{l}\text { 8.6 Title proper } \\
\text { of publisher's } \\
\text { series }\end{array}$ & $\begin{array}{l}\text { Title of the label, as it appears } \\
\text { on the disc. }\end{array}$ & $\begin{array}{l}\text { Disque Pour } \\
\text { Gramophone }\end{array}$ & His Master's Voice \\
\hline $\begin{array}{l}\text { 8.6 Numbering } \\
\text { within } \\
\text { publisher's series }\end{array}$ & Catalogue number & GC 33166 & IR 1009 \\
\hline $\begin{array}{l}\text { 8.9 Standard } \\
\text { number }\end{array}$ & Matrix number & $1356 \mathrm{~F}$ & A23906 \\
\hline 8.8B14 Language & $\begin{array}{l}\text { Select the appropriate } \\
\text { language. }\end{array}$ & French & English \\
\hline Cast note & $\begin{array}{l}\text { Indicate the performer(s), } \\
\text { formatted according to VIAF, } \\
\text { that appear on the recording. } \\
\text { Include voice type or } \\
\text { instrument in brackets. }\end{array}$ & $\begin{array}{l}\text { Ackté, Aino, 1876- } \\
1944 \text { (soprano); } \\
\text { Bourgeois, Émile, } \\
\text { 1857-1934 (piano) }\end{array}$ & $\begin{array}{l}\text { McCormack, John, } \\
\text { 1884-1945 (tenor) ; } \\
\text { Kreisler, Fritz, 1875- } \\
1962 \text { (violin) }\end{array}$ \\
\hline
\end{tabular}

The Stratton-Clarke 78 collection speaks to the collecting practices of two individuals in the twentieth century and is an extensive-if not exhaustive-snapshot of historical recording and performance practices, the artists, the repertoire, and the recording labels during the first half of the twentieth century. As a collection of discrete items, it preserves many early vocal recordings that would otherwise be lost or forgotten. The detailed description of these items, as defined above, ensures that individual recordings are discoverable by researchers. The description of the group of $78 \mathrm{rpm}$ records as an archival collection - rather than simply as discrete items -ensures that their provenance as a collection is preserved and that the curatorial efforts of Stratton and Clarke are known to future users. 


\section{Part Four: Digital Objects and Digitization}

Scope of digital collection

In addition to the physical bulk of the Stratton-Clarke Collection (the $78 \mathrm{rpm}$ and LP records), there is also a good deal of digital content which enhances the value of the collection immensely.

\section{Historic Masters}

Beginning in 1973, Historic Masters issued 78 rpm discs containing unpublished or extremely rare recordings. These were pressed on vinyl from original metal parts in the EMI archive. Over the years, Historic Masters made over 200 reissues in its series, along with many special issues, including some made from old pressings. About a third of these had never been available commercially.

The Stratton-Clarke Collection as transmitted to us includes about 500 transfers from Historic Masters, in flat (archival) and re-engineered versions, stored on hard drive.

\section{Sir Paul Getty Collection}

Sir Paul Getty (1932-2003) was a son of oil tycoon John Paul Getty. Among other things, he was an avid collector of old recordings. The Stratton-Clarke Collection includes about 6,000 digital files from Getty's collection, obtained via Lloyd Stickles, his audio engineer. These were acquired on CDR in WAV format and are now stored on hard drive. Getty's collection numbered some 16,000 78 rpm discs. ${ }^{7}$ It was auctioned off by his estate, making this possibly the largest surviving intact portion of the collection.

\section{Additional material}

There is more digital material from various sources, including a substantial number of cylinder transfers, on DAT, compact disc, or digital files on hard drive. In addition, there are about 5 linear feet of open-reel recordings of vocal music; we have not decided yet on digitization of this material, although we do have the capability in-house.

\section{Local treatment of digital objects}

We are considering several factors regarding the local treatment of digital objects in various formats. Above all is preservation of the original media, or at least the content, at as high a quality as possible.

As we have discovered, there is no such thing as a permanent recording medium. Cylinders are prone to cracking or warping; analogue discs are subject to a variety of physical dangers depending on their composition; audio tape is subject to physical degradation through various mechanisms.

\footnotetext{
${ }^{7}$ Richard Bebb, "I shall go on collecting until I die," The Spectator, https://www.spectator.co.uk/article/-i-shallgo-on-collecting-until-i-die-.
} 
Digital formats promised both durability and higher fidelity. We know now that pressed compact discs are not immune to degradation because of manufacturing defects or improper handling or storage; the dyes in recordable optical discs are not permanent; and DATs, being tapes, are subject to the same types of degradation as analogue tape formats. Digital file formats, whatever the physical media, are not immune to less concrete ravages of time: file formats become obsolete, as do digital storage media, and maintaining hardware for reproduction or storage can be just as challenging for digital media as for analogue.

How do we preserve? The method depends on the medium. In addition, we must triage: what is most at risk now, and what can wait? Due to the COVID shutdown we have not evaluated the collection physically yet, so what follows are the likeliest challenges we will face.

\section{DAT}

Of all the digital formats in the collection, DAT is probably the one most at risk. As audio archiving expert Richard Hess noted on his web site in 2016, "Last decade was a good time to think about migrating DATs to more stable media." ${ }^{8}$ In some circumstances, DATs may be a good candidate for thermal treatment, or "baking," to render them stable enough for transfer, much like open reel tape. This is still an open question.

\section{Compact Disc media}

The Stratton-Clarke Collection includes both commercially released audio compact discs, as well as material on recordable CD stock (mainly $C D-R$ ). In general, the material on $C D-R$ is the priority for transfer. We may make backup copies of commercial CDs following consultation with our Digital Preservation team at the University of Toronto Libraries. Making ISO full-disc copies is more efficient but is not the optimal way to preserve audio CDs. (For a good discussion of the options, there is a post on the subject by Alice Prael on the Saving Digital Stuff blog at Yale University. ${ }^{9}$ )

\section{Hard Drive}

From a physical standpoint, hard drives are the least problematic media. The material still must be examined and processed. We will have to develop methods and standards for such considerations as recording metadata and storage parameters, but these apply to all digital media. This content can be slipstreamed into the digitization/preservation workflow with relatively little preparation.

\footnotetext{
${ }^{8}$ Richard Hess, "Digital Audio," Richard L Hess-AuOdio Tape Restoration Tips \& Notes, 2016, https://richardhess.com/notes/formats/magnetic-media/magnetic-tapes/digital-audio/.

${ }^{9}$ See Alice Prael, "To Image or Copy - the Compact Disc Digital Audio Dilemma," Saving Digital Stuff, December 20, 2016, http://campuspress.yale.edu/borndigital/2016/12/20/to-image-or-copy-the-compact-disc-digital-audiodilemma/.
} 


\section{Opportunities/challenges of digital objects}

There are many opportunities associated with both the maintenance and creation of digital objects, but before we can exploit these, we must first meet the challenges they present.

\section{Challenge: Identifying priorities}

We mentioned triage above; this is the first step. We must carefully examine the material and decide what must be dealt with and when. There is little concern with the analogue media; the discs have been well-stored in a stable environment and have been played in near-optimal conditions. The open-reel tapes may require special treatment, but there are no issues with playback equipment. DATs are an unknown quantity, and along with digital files stored on hard drive, CDs are probably the least at risk.

\section{Challenge: Designing workflows}

The plural is intentional. Diverse media require, to some extent, discrete workflows. More problematic media may require more expertise or experience to process; others may be handled by less experienced staff. At some point the workflows merge; there is also the possibility that some tasks can be done in parallel given sufficient human resources.

\section{Challenge: Infrastructure and storage}

In this case, of course, we are considering digital storage, not shelf space. The main challenge is infrastructure and its associated costs. An example: when the Music Library decided to stream audio of Faculty of Music concerts in the last decade, we had to use tools that were already on hand; there was no budget for any kind of expansion. At one point, for example, we were running the following on a single physical server: our website, several DBTextworks databases, including the one for concert streaming (including storage of the MP3 files that were streamed) and a Microsoft Active Directory domain for the staff, including storage for all user accounts. We were only streaming events that were born digital (recorded directly to CD-R), from 2001 onward. In 2006 we discovered that some of the CD-Rs were degrading. This led to two months of trying to identify problem discs and duplicate/salvage as much as we could from them. After that we devised a new workflow: we ripped WAV files from the original discs using Exact Audio Copy and stored duplicates on DVD. Recordable DVDs are a slightly more robust medium than CD-R, and we did not have the necessary hard drive capacity.

The situation is much different now following the 2016 change in governance structure mentioned in Part One above. The changing relationship between the Music Library, the Faculty of Music, and the University of Toronto Libraries system has been beneficial to all parties. The Music Faculty no longer shoulders the burden of the cost of administering the library, and the Music Library has access to the much greater resources of the central system. We are also taking advantage of the resources of the University of Toronto Archives and Records Management Services. The Music Library archive's web presence is now hosted on UTARMS' Discover Archives platform, and 
although we still host the audio for streaming, it is now on a dedicated server. Eventually it will move to centralized infrastructure. All our uncompressed archival audio is stored on server space managed by the central library system and dedicated to the Music Library, with a proper backup regime. Eventually, all archival audio will also be put into long-term tape storage.

The importance of strong infrastructure, in the form of human and financial resources, server space, digitization equipment, and time, cannot be overstressed. Archival digital audio of a single side of a $78 \mathrm{rpm}$ disc may exist in several formats, in multiple versions:

- Preservation/archival master (raw transfer; no enhancements or editing),

- Production master (may be the same as preservation master; may be edited to split a file into parts, or combine files that could not be created as one during digitization), and

- Derivative files, i.e. files edited or enhanced for presentation or reproduction in various formats, resolutions, with or without compression.

In the Internet Archive's 78s project, for example, each disc is recorded 4 times simultaneously, using different styli. These are recorded flat, and then with the appropriate equalization curve applied. An engineer recommends the optimal version for playback. All the transfers, flat and equalized, are available for listening or download.

This is a massive storage load, even without accounting for backup files. Even without that level of duplication, storage space for digital objects is paramount. Fortunately, 1 terabyte of storage space takes up much less physical space than 6,000 discs.

\section{Opportunity: Presentation}

This is where challenges and opportunities intersect. What bigger opportunity than to be able to present your collection to the world?

Classroom teaching will be one of the core purposes of the Stratton-Clarke Collection, and the "media cart" mentioned in Part One above supports that. This collection complements the Faculty of Music's robust programs in vocal music. These include both undergraduate and graduate degrees, a performer's diploma, and the Faculty's renowned opera school. The equipment will help to make the collection available for in-person research. Given our capacity in the area of digital preservation and access, and the current COVID pandemic, we have every reason to plan online methods of sharing this treasure with the wider world.

The Music Library has been engaged in digitization, digital exhibitions, and streaming work for several years. As mentioned above, our Faculty Events database with links to streaming audio, originally hosted in-house, now resides on the UTARMS Discover Archives platform. The archive of the Canadian violinist Kathleen Parlow was digitized several years ago, and this material is available for public viewing both on the Internet Archive and the Library's Islandora platform. 
We expect to be able to meet the challenges and take advantage of the opportunities the StrattonClarke Collection provides. With the equipment and funding that come with the collection, recent administrative changes in the Music Library, along with our existing capabilities, we hope to exceed expectations.

Occasionally, digitization projects produce ancillary benefits. For the Music Library, the digitization of the Kathleen Parlow collection yielded such a result. When the collection reached the Music Library in the 1960s, one piece of music was diverted to the Faculty's collection of performance materials: a full score and set of parts, in manuscript, for a violin concerto by the Norwegian composer Johan Halvorsen. What was not known at the time was that this concerto, composed in 1909 , had been considered lost for decades; indeed, thought to have been withdrawn and destroyed by the composer himself. (In fact, according to Grove Music Online, it is still missing. ${ }^{10}$ ) Now we have scanned, edited, and published it to great fanfare, especially in Norway.

\section{Summary}

The Stratton-Clarke Collection gives Music Library staff the opportunity to develop project management, workflow design, preservation, digitization, and access skills that will be essential as we look to the future.

Along the way we have strengthened our relationship with the Central Libraries' IT and Digital Preservation departments, our understanding of their capacity and priorities, the tools they use, and how we can fit our projects into their workflows and priorities. We have also developed a partnership with the team at Downsview, purchased reusable shipping bins for transferring LPs and archival collections en masse. Since 2017, both the Directors of Advancement for Music and for the Libraries retired, so we have had to be ready to make connections and reach out to the new officers to ensure they are up to speed with this donation.

We foresee this collection being very interesting to researchers now and in the future. One might examine early recording practice for singers: for example, how to balance singers and instrumentalists before microphones came into use. One could also study vocal performance practice through the first half of the twentieth century, early recording technologies and techniques. We also see opportunities for a lecture series in the Music Library highlighting elements of this collection. We would like to do an oral history with Stephen Clarke to capture his knowledge of, and the stories behind, the collection. Now that we have received the collection we look forward to processing and promoting it once COVID-19 restrictions are lifted.

\footnotetext{
${ }^{10}$ Øyvin Dybsand, "Halvorsen, Johan," Grove Music Online, 2001, https://www.oxfordmusiconline.com Lgrovemusic/view/10.1093/gmo/9781561592630.001.0001/omo-9781561592630-e-0000012262.
} 


\section{Bibliography}

Ashbrook, Williams. "The Mapleson Cylinders: Complete Edition, 1900-1904." The Opera Quarterly 4, no. 2 (January 1986): 110-116. doi:10.1093/oq/4.2.110.

Bebb, Richard. "I shall go on collecting until I die." The Spectator, https://www.spectator.co.uk/article/-i-shall-go-on-collecting-until-i-die-.

Dybsand, Øyvin. "Halvorsen, Johan." Grove Music Online, 2001, https://www.oxfordmusiconline.com /grovemusic/view/10.1093/gmo/9781561592630.001.0001/omo-9781561592630-e0000012262

Hess, Richard. "Digital Audio." Richard L Hess-AuOdio Tape Restoration Tips \& Notes, 2016, https://richardhess.com/notes/formats/magnetic-media/magnetic-tapes/digital-audio/.

Prael, Alice. "To Image or Copy - the Compact Disc Digital Audio Dilemma." Saving Digital Stuff, December 20, 2016, http://campuspress.yale.edu/borndigital/2016/12/20/to-image-or-copythe-compact-disc-digital-audio-dilemma/. 